\title{
On the use of triethylamine hydroiodide as a supporting electrolyte in dye-sensitized solar cells
}

\author{
Jian-Ging Chen ${ }^{\mathrm{a}}$, Vembu Suryanarayanan ${ }^{\mathrm{a}}$, Kun-Mu Lee ${ }^{\mathrm{b}}$, Kuo-Chuan Ho ${ }^{\mathrm{a}, \mathrm{b}, *}$ \\ ${ }^{a}$ Department of Chemical Engineering, National Taiwan University, Taipei 10617, Taiwan \\ ${ }^{\mathrm{b}}$ Institute of Polymer Science and Engineering, National Taiwan University, Taipei 10617, Taiwan
}

Available online 9 May 2007

\begin{abstract}
For the first time, the application of a molten salt, triethylamine hydroiodide (THI), as a supporting electrolyte was investigated for the dye-sensitized solar cells (DSSCs). Titanium dioxide $\left(\mathrm{TiO}_{2}\right)$ electrode was modified by incorporation of high- and low-molecular weight poly(ethylene glycol) along with $\mathrm{TiO}_{2}$ nanoparticles of two different sizes $(300 \mathrm{~nm}(30 \mathrm{wt} \%)$ and $20 \mathrm{~nm}(70 \mathrm{wt} \%))$. The highest apparent diffusion coefficient $(D)$ of $8.12 \times 10^{-6} \mathrm{~cm}^{2} \mathrm{~s}^{-1}$ was obtained for $\mathrm{I}^{-}(0.5 \mathrm{M}$ of THI) from linear sweep voltammetry (LSV). Short-circuit current density $\left(J_{\mathrm{sc}}\right)$ increases with the concentration of THI whereas open-circuit potential ( $\left.V_{\mathrm{oc}}\right)$ remains the same. Optimum $J_{\mathrm{sc}}$ $\left(19.28 \mathrm{~mA} \mathrm{~cm}^{-2}\right)$ and $V_{\mathrm{oc}}(0.7 \mathrm{~V})$ with a highest conversion efficiency $(\eta)$ of $8.45 \%$ were obtained for the DSSC containing $0.5 \mathrm{M}$ of THI/ $0.05 \mathrm{M} \mathrm{I}_{2} / 0.5 \mathrm{M} \mathrm{TBP}$ in $\mathrm{CH}_{3} \mathrm{CN}$. It is also observed that the $J_{\mathrm{sc}}$ and $\eta$ of the DSSC mainly relates with the $D$ values of $\mathrm{I}^{-}$and chargetransfer resistances such as $R_{\mathrm{ct} 1}$ and $R_{\mathrm{ct} 2}$ operating along $\mathrm{Pt} / \mathrm{TiO}_{2}$ electrolyte interface, obtained from LSV and electrochemical impedance spectroscopy (EIS). For comparison, tetraethylammonium iodide (TEAI) and LiI were also selected as supporting electrolytes. Though both the THI and TEAI have similar structures, replacement of one methyl group by hydrogen improves the efficiency of the DSSC containing the former electrolyte. Further, the DSSC containing THI exhibits higher $J_{\text {sc }}$ and $\eta$ than LiI (7.70\%), from which it is concluded that THI may be used as an efficient and alternative candidate to replace LiI in the current research of DSSCs. (C) 2007 Elsevier B.V. All rights reserved.
\end{abstract}

Keywords: Dye-sensitized solar cells; Nanocrystallined $\mathrm{TiO}_{2}$; Supporting electrolyte; Triethylamine hydroiodide

\section{Introduction}

Because of high photon-to-electron power conversion efficiency and low production cost, dye-sensitized solar cells (DSSCs) have been established as the promising alternative to silicon solar cells [1,2]. The device is composed of three adjacent thin layers such as a high band-gap nanocrystalline semiconductor coated with a dye sensitizer for the absorption in the visible region, a platinized counter electrode for the collection of electrons and a redox electrolyte, sandwiched between two transparent conducting oxide (TCO) electrodes. The usual choice for the semiconductor material is titanium dioxide

\footnotetext{
*Corresponding author. Department of Chemical Engineering, National Taiwan University, Taipei 10617, Taiwan.

Tel.: + 886223660739 ; fax: + 886223623040 .

E-mail address: kcho@ntu.edu.tw (K.-C. Ho).
}

$\left(\mathrm{TiO}_{2}\right)$, whereas ruthenium bipyridyl derivatives are for the dye sensitizer $[3,4]$. The electrolyte contains $\mathrm{I}_{3}^{-} / \mathrm{I}^{-}$redox couple, which was obtained by the mixing of iodine $\left(\mathrm{I}_{2}\right)$ and inorganic or organic iodides in suitable non-aqueous solvents. The role of the electrolyte is very important as it provides the internal electric conductivity by diffusing among semiconductor nanoparticles and sets the potential barrier necessary for the energy conversion. In addition, it helps for the dye regeneration by the charge-transfer reaction with the dye molecule [5].

The conventional inorganic and organic iodide electrolyte salts are lithium and tetra-alkyl ammonium iodides. Besides this, several molten salts, particularly ionic liquidbased imidazolinium salts, have also been used for improving the performance of the DSSCs [6-10]. In these works, cations play an important role for the highconversion efficiency. For example, the interaction of $\mathrm{Li}^{+}$ with $\mathrm{TiO}_{2}$ enhances the electron transfer from the 
sensitized dye to the $\mathrm{TiO}_{2}$ and from $\mathrm{I}^{-}$to the oxidized dye, leading to high photocurrent [11-13]. In a similar manner, the multilayer adsorption of the imidazolinium cations lead to the increase of electron diffusion coefficient with increasing concentration of cations, leading to improvement in the DSSC performance [14]. Kubo et al. [10] further studied the effect of the alkyl chain length of some imidazolium cations on the electron recombination lifetime. They found that the chain length does affect the electron recombination lifetime. The lifetime increased with the increase in the alkyl chain length. This is because hydrophobic alkyl chains may impede $\mathrm{I}_{3}^{-}$from reaching $\mathrm{TiO}_{2}$. The result reveals that bigger cations may enhance photocurrent due to the lower probability of electron recombination. Along this line, for the first time, we are going to investigate here about the photovoltaic application of a novel electrolyte, triethylamine hydroiodide (THI), an efficient and alternative candidate to LiI, on the photovoltaic performance of the DSSC.

\section{Experimental}

Ammonium iodide $\left(\mathrm{NH}_{4} \mathrm{I}\right)$ and triethylamine $\left(\left(\mathrm{C}_{2} \mathrm{H}_{5}\right)_{3} \mathrm{~N}\right)$ were purchased from Acros $(99+\%)$ and Sigma $(99+\%)$, respectively. LiI, $\mathrm{I}_{2}, \mathrm{CH}_{3} \mathrm{CN}$, tertiary butanol, poly(ethylene glycol) (PEG) and 4-tertiary butyl pyridine (TBP) were obtained from Merck and titanium (V) isopropoxide (98\%) was from Acros. The N3 dye was the commercial product obtained from Solaronix S.A., Aubonne, Switzerland.

THI was prepared by mixing an aqueous solution of $\mathrm{NH}_{4} \mathrm{I}(20-30 \%, \mathrm{w} / \mathrm{v})$ and a slight excess of the triethylamine in water $(70 \%, \mathrm{v} / \mathrm{v})$ with constant stirring under inert atmosphere and this mixture was heated at a temperature of $80^{\circ} \mathrm{C}$ till the evolution of ammonia would be ceased [15]. During the initial stage of the preparation, ethanol was added to the reaction mixture to prevent phase separation. THI was formed according to the chemical reaction

$$
\left(\mathrm{C}_{2} \mathrm{H}_{5}\right)_{3} \mathrm{~N}+\mathrm{NH}_{4} \mathrm{I} \stackrel{\Delta}{\longrightarrow}\left(\mathrm{C}_{2} \mathrm{H}_{5}\right)_{3} \mathrm{NHI}+\mathrm{NH}_{3} \text {. }
$$

After the completion of the reaction, the residual solution was removed from the flask and ethanol was removed from the product on a rotary evaporator. Finally, a white solid residue was obtained. The solid was recrystallized from ethyl acetate-ethanol mixture $(1: 1, \mathrm{v} / \mathrm{v})$ and it was dried in a vacuum oven at $80^{\circ} \mathrm{C}$. The melting point $\left(185^{\circ} \mathrm{C}\right)$ and ${ }^{1} \mathrm{H}$ NMR spectrum of the product agrees well with standard (Showa, Japan), confirming the purity of the sample.

The $\mathrm{TiO}_{2}$ precursor was prepared by sol-gel method according to the procedure reported in the literature [16]. Titanium (IV) isopropoxide ( $72 \mathrm{ml}, 98 \%$, Across) was added to $430 \mathrm{ml}$ of a $0.1 \mathrm{M}$ nitric acid solution with constant stirring and heated to $85^{\circ} \mathrm{C}$ simultaneously for $8 \mathrm{~h}$. When the mixture was cooled down to room temperature, the resultant colloid was filtered, and heated in an autoclave at $240^{\circ} \mathrm{C}$ for $12 \mathrm{~h}$ in order to allow the $\mathrm{TiO}_{2}$ particles to grow uniformly (ca. $20 \mathrm{~nm}$ ). Consequently, the $\mathrm{TiO}_{2}$ colloid was concentrated to $13 \mathrm{wt} \%$ (with respect to the $\mathrm{TiO}_{2}$ ) and two types of pastes were prepared by the addition $30 \mathrm{wt} \%$ (with respect to the $\mathrm{TiO}_{2}$ ) of PEG to the above solution in order to control the pore diameters and to prevent the film from cracking during drying.

The $\mathrm{TiO}_{2}$ photoelectrode was prepared by subsequent coating of four types of $\mathrm{TiO}_{2}$ paste on a conducting fluorine-doped tin oxide (FTO) glass (with a sheet resistivity of $15 \Omega /$ sq., obtained from Hartford Glass Co. Inc.) using glass rod [3]. For the first two coatings, the $\mathrm{TiO}_{2}$ pastes incorporated with PEG having a molecular weight of 200,000 was used followed by third coating with the $\mathrm{TiO}_{2}$ paste containing PEG of MW 20,000. The final coating was carried out with mixture containing lightscattering particles of $\mathrm{TiO}_{2}(300 \mathrm{~nm}(30 \mathrm{wt} \%)$ and $20 \mathrm{~nm}$ $(70 \mathrm{wt} \%))$ for reducing the light loss by back scattering.

An active area of $0.25 \mathrm{~cm}^{2}$ was selected from sintered electrode and the electrodes were immersed in $3 \times 10^{-4} \mathrm{M}$ solution of cis-di(thiocyanato)bis(2,2'-bipyridyl-4,4'-dicarboxylate)ruthenium (II) (N3) containing acetonitrile and tertiary butanol (in the volume ratio of 1:1) overnight. A platinum-sputtered FTO $(15 \Omega /$ sq.) conducting glass plate (Pt thickness of $100 \mathrm{~nm}$ ) was used as the counter electrode and the electrolyte was composed of different concentrations of the THI in $\mathrm{CH}_{3} \mathrm{CN}$ containing $0.05 \mathrm{M}$ iodine $\left(\mathrm{I}_{2}\right)$ and $0.5 \mathrm{M}$ tertiary butylpyridine (TBP). The electrolyte solution was sprayed on both the dye-immobilized photoanode and Pt-sputtered FTO glass and they are physically sandwiched together using cell holders immediately.

The cell was illuminated by an Oriel solar simulator (\#6266) equipped with a water-based IR filter under AM 1.5 filter (Oriel, \#81075) irradiation. The photoelectrochemical characteristics of the DSSCs were recorded with a potentiostat/galvanostat (PGSTAT 30, Autolab, EcoChemie, The Netherlands). Electrochemical impedance spectra (EIS) were obtained by the above-mentioned potentiostat/galvanostat equipped with FRA2 module under constant light illumination of $100 \mathrm{~mW} / \mathrm{cm}^{2}$. The frequency range explored was $10 \mathrm{mHz}-65 \mathrm{kHz}$. The applied bias voltage and AC amplitude were set at open-circuit voltage of the DSSCs and $10 \mathrm{mV}$, respectively, between the FTO-Pt counter electrode and the $\mathrm{FTO}-\mathrm{TiO}_{2}$-dye working electrode, starting from the short-circuit condition. The impedance spectra were analyzed by an equivalent circuit model interpreting the characteristics of the DSSCs [17,18].

\section{Results and discussions}

Before going to study about the photovoltaic performance of the DSSC containing THI, both the ionic conductivities and the diffusion coefficients $(D)$ for various concentrations of the THI in $\mathrm{CH}_{3} \mathrm{CN}$ were optimized. Fig. 1 shows the relationship between the ionic conductivity and various concentrations of the THI in acetonitrile at room temperature $\left(25^{\circ} \mathrm{C}\right)$. From this, we suggest that $0.5 \mathrm{M} \mathrm{THI}$ is the optimum concentration in acetonitrile as 


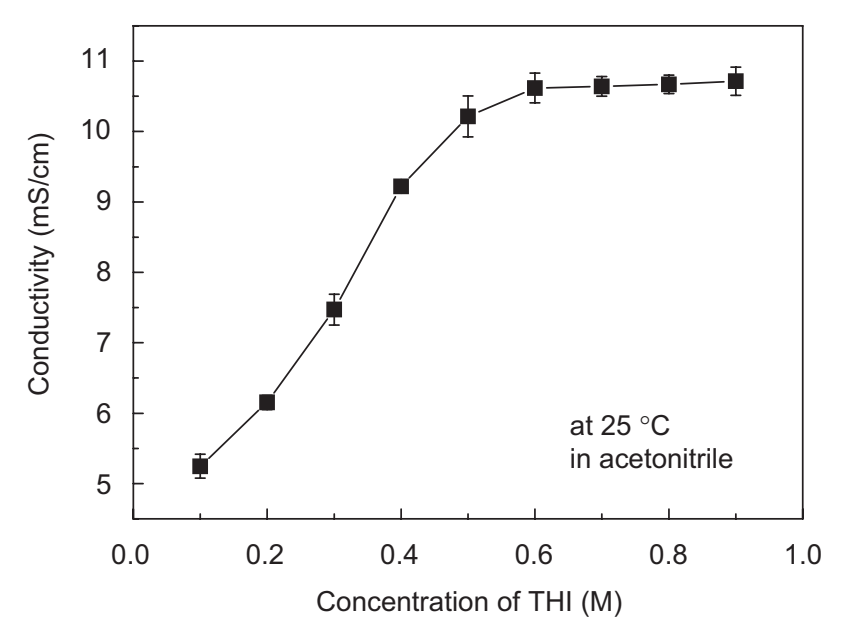

Fig. 1. The relationship between the ionic conductivity and various concentrations of the THI in acetonitrile at room temperature $\left(25^{\circ} \mathrm{C}\right)$.

an electrolyte for the DSSCs. The linear sweep voltammograms (LSVs) of different concentrations of $\mathrm{THI} / \mathrm{I}_{2}$ in $\mathrm{CH}_{3} \mathrm{CN}$ (samples a-h) on a $\mathrm{Pt}$ microelectrode at a sweep rate of $0.05 \mathrm{mV} \mathrm{s}^{-1}$ are shown in Fig. 2. The LSVs were recorded only in the anodic side and concentration of $\mathrm{I}_{2}$ was kept the same $(0.05 \mathrm{M})$. Anodic currents are not affected with higher sweep rates, suggesting that steadystate currents controlled by the diffusion of iodide $\left(\mathrm{I}^{-}\right)$ have been attained. The apparent diffusion coefficient $(D)$ values of $\mathrm{I}^{-}$can be calculated from anodic and cathodic steady-state currents $\left(i_{\mathrm{s}}\right)$ according to the following equation

$i_{\mathrm{s}}=4 n F D r_{\mathrm{o}} C$,

where $i_{\mathrm{s}}$ is the steady-state current, $n$ is the number of electron transfer taking place in the electrochemical reaction, $D$ is the apparent diffusion coefficient, $r_{\mathrm{o}}$ is the radius of the $\mathrm{Pt}$ microelectrode and $C$ is the concentration of the reactive species. The $D$ values of $\mathrm{I}^{-}$obtained from the above voltammograms, for samples $\mathrm{a}-\mathrm{h}$, are shown Table 1. The $D$ value for sample a was very low $\left(3.34 \times 10^{-6} \mathrm{~cm}^{2} \mathrm{~s}^{-1}\right)$ and with increase in concentrations of the THI from $0.1 \mathrm{M}, D$ value increases (samples b-d) and at $0.5 \mathrm{M}$ (sample e), the highest $D$ value of $8.12 \times 10^{-6} \mathrm{~cm}^{2} \mathrm{~s}^{-1}$ (an almost 2.5 times more than the value at $0.1 \mathrm{M}$ ) was noted. However, further increase in the concentration of the THI (samples $\mathrm{f}-\mathrm{h}$, Table 1) has almost negligible effect.

The corresponding photoelectrochemical curves $(I-V)$ of the eight DSSCs (cells $\mathrm{A}-\mathrm{H}$ ) associated with different concentrations of the THI in $\mathrm{CH}_{3} \mathrm{CN}$ (samples $\mathrm{a}-\mathrm{h}$ ) are shown in Fig. 3 and the photovoltaic parameters obtained from the $I-V$ curves were tabulated in Table 2. Cell A shows a low short-circuit current density $\left(J_{\mathrm{sc}}\right)$ of $6.64 \mathrm{~mA} \mathrm{~cm}^{-2}$ and the $J_{\mathrm{sc}}$ enhances with the increase in concentrations of THI (cells B-D). At $0.5 \mathrm{M}$ (cell E), a $J_{\mathrm{sc}}$ value of $19.28 \mathrm{~mA} \mathrm{~cm}^{-2}$ was obtained (three times increase) and further increase in THI concentration leads to slight decrease in the $J_{\text {sc }}$. (Fig. 3, inset). The results obtained in

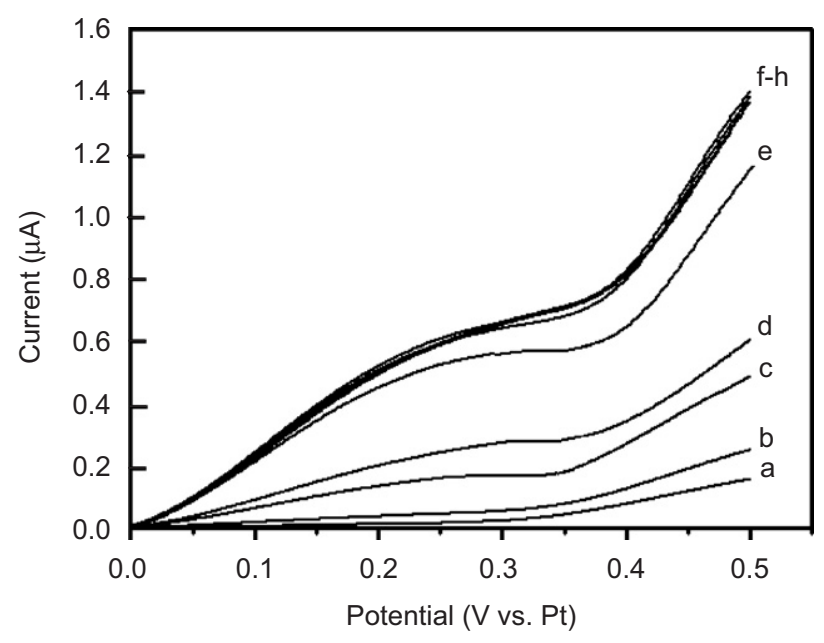

Fig. 2. The linear sweep voltammograms obtained for different concentrations of the THI (samples a-h) in $\mathrm{CH}_{3} \mathrm{CN}$ on a Pt microelectrode at a sweep rate of $0.05 \mathrm{mV} \mathrm{s}^{-1}$.

Table 1

The diffusion coefficients of $\mathrm{I}^{-}$as a function of the THI concentration

\begin{tabular}{lll}
\hline Samples & Concentrations of THI $(\mathrm{M})$ & $D\left(10^{-6} \mathrm{~cm}^{2} / \mathrm{s}\right)$ \\
\hline $\mathrm{a}$ & 0.1 & 3.34 \\
$\mathrm{~b}$ & 0.2 & 5.52 \\
$\mathrm{c}$ & 0.3 & 6.56 \\
$\mathrm{~d}$ & 0.4 & 7.56 \\
$\mathrm{e}$ & 0.5 & 8.12 \\
$\mathrm{f}$ & 0.6 & 8.03 \\
$\mathrm{~g}$ & 0.7 & 7.96 \\
$\mathrm{~h}$ & 0.8 & 7.89 \\
\hline
\end{tabular}

this study agree well with the results obtained from the dependence of the $D$ values of $\mathrm{I}^{-}$as a function of the THI concentration. This comparison has been presented in the inset of Fig. 3. In contrast, the open-circuit voltage $\left(V_{\text {oc }}\right)$ remains almost the same. For the first time, an excellent conversion efficiency $(\eta)$ of $8.45 \%$ with a fill factor of 0.62 was obtained in this work in the absence of other conventional electrolytes such as LiI.

Impedance measurements were performed for the DSSC associated with different concentrations of the THI under constant light illumination and open-circuit condition and the frequency range explored was $10 \mathrm{mHz}-65 \mathrm{kHz}$. Because of a non-uniform distribution of current due to nonsmooth surface of the $\mathrm{TiO}_{2}$ film and $\mathrm{Pt}$ electrode, the constant phase element (CPE) acting as the capacitance, was used to fit the experimental data more accurately. It is a non-ideal frequency-dependent capacitance, used for fitting depressed semicircles in Nyquist plots obtained by the equation $Z=1 /\left[T\left(i^{\prime} \times \omega\right)^{P}\right]$, where $T$ and $P$ are the constant phase element parameters, and $i$ represents the complex conjugate, $\omega$ is the angular frequency of the AC signal, respectively [19].

Fig. 4 shows the EIS spectra of the DSSC fabricated with different concentrations of the THI (cells $\mathrm{A}-\mathrm{H}$ ) under 


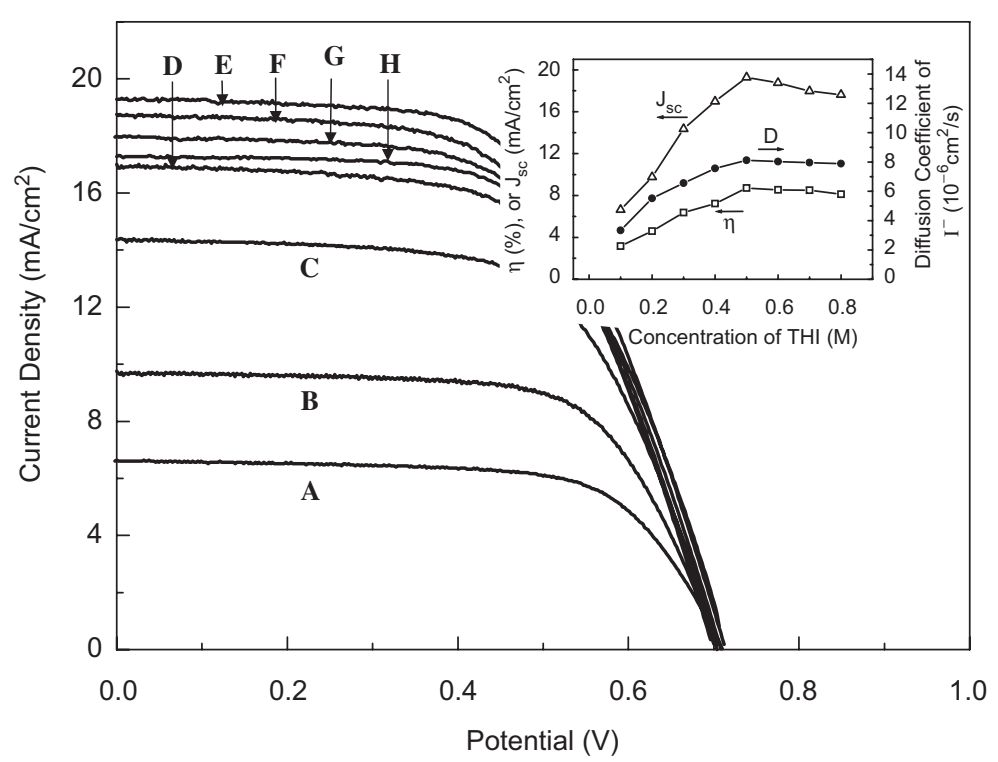

Fig. 3. The photoelectrochemical characteristics of the DSSCs (cells A-H) associated with different concentrations of the $\mathrm{THI}^{\mathrm{A}} \mathrm{C} \mathrm{CH}_{3} \mathrm{CN}$ at a constant illumination of $100 \mathrm{~mW} / \mathrm{cm}^{2}$. The inset shows the dependence of different concentrations of the THI on $J_{\mathrm{sc}}, \eta$ and $D$ values of $\mathrm{I}^{-}$. The concentrations of $\mathrm{I}_{2}$ and TBP are kept at 0.05 and $0.5 \mathrm{M}$, respectively.

Table 2

The photovoltaic parameters of the DSSCs containing various THI concentrations

\begin{tabular}{lllll}
\hline Cells & $J_{\mathrm{sc}}\left(\mathrm{mA} / \mathrm{cm}^{2}\right)$ & $V_{\text {oc }}(\mathrm{V})$ & FF & $\eta(\%)$ \\
\hline A & 6.64 & 0.70 & 0.61 & 3.17 \\
B & 9.76 & 0.70 & 0.63 & 4.60 \\
C & 14.36 & 0.70 & 0.64 & 6.37 \\
D & 16.98 & 0.70 & 0.63 & 7.23 \\
E & 19.28 & 0.71 & 0.62 & 8.45 \\
F & 18.76 & 0.70 & 0.64 & 8.17 \\
G & 17.97 & 0.71 & 0.63 & 7.92 \\
H & 17.22 & 0.71 & 0.63 & 7.76 \\
\hline
\end{tabular}

Experimental conditions are the same as in Fig. 3.

identical experimental conditions. Experimental data are represented by the symbols while the solid lines correspond to the fit using the equivalent circuit model inserted in the inset of Fig. 4. The ohmic serial resistance $\left(R_{\mathrm{s}}\right)$ corresponds to the series resistance and the resistances $R_{\mathrm{ct} 1}$ and $R_{\mathrm{ct} 2}$ relate to charge-transfer processes occurring at the solvent interfaces of $\mathrm{Pt}$ counter electrode and $\mathrm{TiO}_{2}$ film, respectively $[20,21]$. The third semicircle in both the conditions represents the Warburg resistance coefficients. From this figure, it is interesting to note that both $R_{\mathrm{ct} 1}$ and $R_{\mathrm{ct} 2}$ of the DSSC decrease with the increase in the THI concentration and remain almost the same with the increase in the THI concentration beyond $0.5 \mathrm{M}$ (inset of Fig. 4).

The photovoltaic performance of the DSSC-containing THI is also compared with other solar cells containing tetraethylammonium iodide (TEAI) and LiI. Here, the reason for selecting TEAI as the supporting electrolyte is that both of them (TEAI and THI) have similar structure except the existence of one hydrogen molecule in the THI instead of ethyl group (Scheme 1).

The LiI has still been used as the successful candidate for generating $\mathrm{I}^{-}$during the photoelectrochemical reaction, since it offers maximum conversion efficiency in all the liquid-type solar cells and hence the comparison was carried out.

It is important here to note that it is very difficult to obtain higher concentrations of TEAI in $\mathrm{CH}_{3} \mathrm{CN}$, as it shows poor solubility in this medium and only $0.1 \mathrm{M}$ of the THI in $\mathrm{CH}_{3} \mathrm{CN}$ was prepared. As a result of this, photovoltaic characteristics of the DSSCs were compared under the identical concentration $(0.1 \mathrm{M})$ of THI and TEAI. Fig. 5a and $\mathrm{b}$ show such investigations on the DSSCs containing TEAI and THI $(0.1 \mathrm{M})$ and LiI and THI $(0.5 \mathrm{M})$, respectively. Though the $V_{\mathrm{oc}}$ of the DSSC containing TEAI is slightly higher than THI, high $J_{\mathrm{sc}}$ (an approximately 1.6 times more) was noted in the solar cell containing THI (Fig. 5a). This may be due to higher dissociation of $\mathrm{I}^{-}$in the case of THI when compared to TEAI by inductive effect $\left(\mathrm{I}^{-}\right)$operating on $\mathrm{N}^{+}$which helps for the facile formation of more redox species $\left(\mathrm{I}^{-} / \mathrm{I}_{3}^{-}\right)$.

Under identical concentrations and experimental conditions, the DSSCs containing LiI and the THI show the same $V_{\text {oc }}$. However, higher $J_{\text {sc }}$ was noted for the solar cell containing THI than LiI (Fig. 5b); the conversion efficiency of the DSSCs containing THI and LiI were $8.45 \%$ and $7.70 \%$, respectively, which shows that the THI can be used as an alternative supporting electrolyte for the LiI in the DSSC. It is well known that the LiI is highly hygroscopic and in order to eliminate the effect of moisture during photoelectrochemical reaction, assembling of the DSSC with the LiI needs sophisticated glove box. On the other hand, THI is highly stable in air and its use makes the 


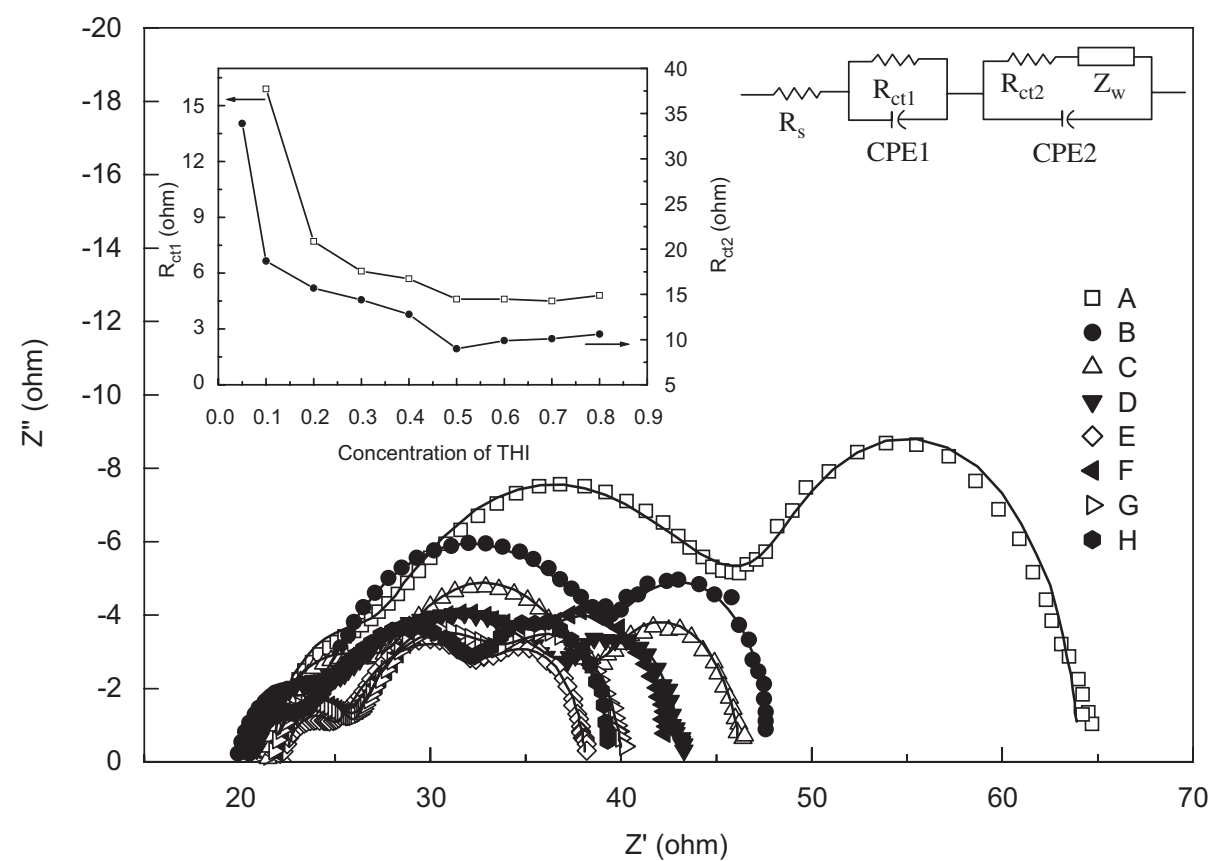

Fig. 4. EIS spectra of the DSSCs (cells A-H) fabricated with different THI concentrations in $\mathrm{CH}_{3} \mathrm{CN}$ at a constant illumination of $100 \mathrm{~mW} / \mathrm{cm}^{2}$. Experimental results are represented by symbols while the straight lines correspond to fit. The insets show the equivalent circuit and the dependence of $R_{\mathrm{ct} 1}$ and $R_{\mathrm{ct} 2}$ as a function of THI concentration. Other conditions are the same as those in Fig. 2.

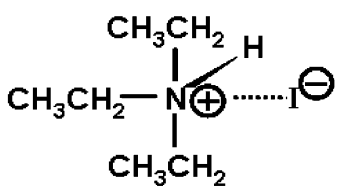

THI

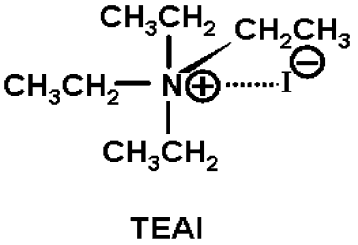

Scheme 1

procedure very easy and simple. On this basis, the use of THI would be certainly beneficial for the DSSC research in the near future.

\section{Conclusion}

For the first time, photoelectrochemical characteristics of the DSSC containing THI in $\mathrm{CH}_{3} \mathrm{CN}$ were studied in this work. The highest $D$ value of $8.12 \times 10^{-6} \mathrm{~cm}^{2} \mathrm{~s}^{-1}$ was obtained for $\mathrm{I}^{-}$at $0.5 \mathrm{M}$ of THI. It is also observed that $J_{\text {sc }}$ and conversion efficiency of the DSSC mainly relate with the $D$ values of $\mathrm{I}^{-}$and charge-transfer resistances such as $R_{\mathrm{ct} 1}$ and $R_{\mathrm{ct} 2}$ operating along $\mathrm{Pt}$ and $\mathrm{TiO}_{2}$ electrolyte interface, obtained from EIS. Under identical concentrations and conditions, the DSSC containing THI shows higher $J_{\mathrm{sc}}$ than its corresponding counterpart TEAI. Further, better conversion efficiency $(\eta=8.45 \%)$ was obtained for the DSSC containing THI when compared to LiI $(\eta=7.70 \%)$ and this shows that THI may be used as

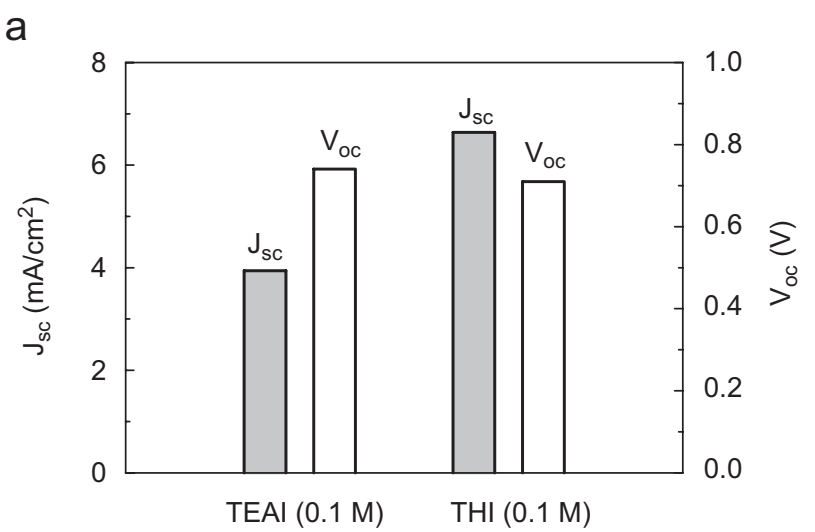

b

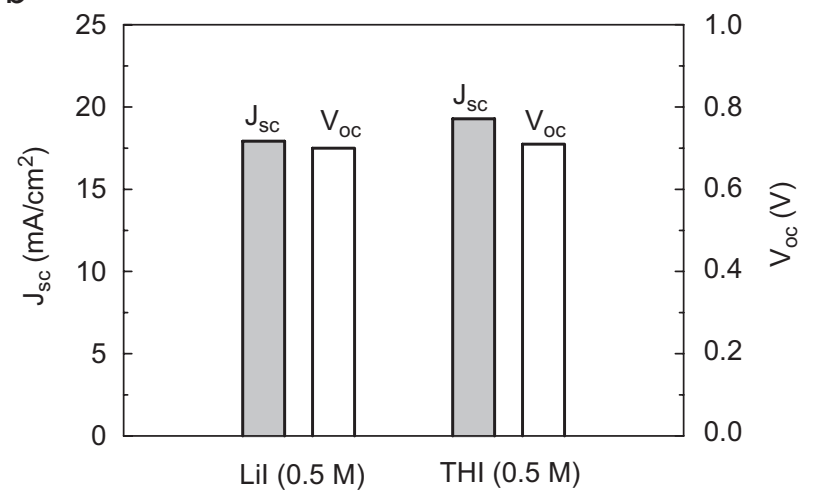

Fig. 5. The comparison on the $J_{\mathrm{sc}}$ and $V_{\mathrm{oc}}$ of the DSSCs containing different electrolytes. (a) TEAI and THI $(0.1 \mathrm{M})$ and (b) LiI and THI $(0.5 \mathrm{M})$ at a constant illumination of $100 \mathrm{~mW} / \mathrm{cm}^{2}$. 
an efficient and alternative candidate to replace LiI in the current research of DSSCs.

\section{Acknowledgments}

This work was financially supported by the Academia Sinica, Taipei, Taiwan, the Republic of China, under grant AS-94-TP-A02. Helpful discussions with Professor TienYau Luh, of Department of Chemistry, National Taiwan University, are appreciated. This work was also partially supported by the Photovoltaics Technology Center, Industrial Technology Research Institute (ITRI), Chutung, Hsinchu, Taiwan.

\section{References}

[1] M.K. Nazeeruddin, A. Kay, I. Rodicio, R. Humphry-Baker, E. Muller, P. Liska, N. Vlachopoulos, M. Grätzel, J. Am. Chem. Soc. 115 (1993) 6382.

[2] M. Grätzel, J. Photochem. Photobiol. C: Photochem. Rev. 4 (2003) 145.

[3] M.K. Nazeeruddin, P. Pechy, T. Renouard, S.M. Zakeeruddin, R. Humphry-Baker, P. Comte, P. Liska, L. Cevery, E. Costa V. Shklover, L. Spiccia, G.B. Deacon, C.A. Bignozzi, M. Grätzel, J. Am. Chem. Soc. 123 (2001) 1613.

[4] M. Grätzel, J. Photochem. Photobiol. A: Chem. 164 (2004) 3.

[5] E. Stathatos, P. Lianos, S.M. Zakeeruddin, P. Liska, M. Grätzel, Chem. Mater. 15 (2003) 1825.
[6] W. Kubo, K. Murakoshi, T. Kitamura, S. Yoshida, M. Haruki, K. Hanabusa, H. Shirai, Y. Wada, S. Yanagida, J. Phys. Chem. B 105 (2001) 12809.

[7] S. Mikoshiba, S. Murai, H. Sumino, S. Hayase, Chem. Lett. 4 (2002) 918.

[8] P. Wang, S.M. Zakeeruddin, I. Exnar, M. Grätzel, Chem. Commun. (2002) 2972.

[9] P. Wang, S.M. Zakeeruddin, P. Comte, I. Exnar, M. Grätzel, J. Am. Chem. Soc. 125 (2003) 1166.

[10] W. Kubo, S. Kambe, S. Nakade, T. Kitamura, K. Hanabusa, Y. Wada, S. Yanagida, J. Phys. Chem. B 107 (2003) 4374.

[11] S.A. Haque, Y. Tachibana, R.L. Willis, J.E. Moser, M. Grätzel, D.R. Klug, J.R. Durrant, J. Phys. Chem. B 104 (2000) 538.

[12] K. Hara, T. Horiguchi, T. Kinoshita, K. Sayama, H. Arakawa, Sol. Energy Mater. Sol. Cells 70 (2001) 151.

[13] M. Wagemaker, A.P.M. Kentgens, F.M. Mulder, Nature 418 (2002) 397.

[14] S. Kambe, S. Nakade, T. Kitamura, Y. Wada, S. Yanagida, J. Phys. Chem. B 106 (2002) 2967.

[15] M.E. Coddens, K.G. Furton, C.F. Poole, J. Chromatogr. 356 (1986) 59.

[16] C.J. Barbé, F. Árendse, P. Comte, M. Jirousek, F. Lenzmann, V. Shklover, M. Grätzel, J. Am. Ceram. Soc. 80 (1997) 3157.

[17] C. Longo, J. Freitas, M.A. De Paoli, J. Photochem. Photobiol. A: Chem. 159 (2003) 33.

[18] C. Longo, M.A. De Paoli, J. Braz. Chem. Soc. 14 (2003) 889.

[19] G.T.K. Fey, J.G. Chen, V. Subramanian, T. Osaka, J. Power Sources 112 (2002) 384.

[20] C. Longo, A.F. Nogueira, M.A. De Paoli, H. Cachet, J. Phys. Chem. B 106 (2002) 5925.

[21] J. van de Lagemaat, N.G. Park, A.J. Frank, J. Phys. Chem. B 104 (2000) 2044. 